\title{
PROJETO PIMPEX BH - PIMP MY CARROÇA: ERGONOMIA, PESQUISA E DESENVOLVIMENTO DE CARROÇAS DE CATADORES DE RECICLÁVEIS
}

Luciana dos Santos Duarte

Faculdades Kennedy

santosduarte.luciana@gmail.com

Silvia Resende Xavier

Parsons School of Design

silviarx@gmail.com
Marcel Yssamo Matssunaka

Projeto Pimp My Carroça

paraomarcel@gmail.com

Thiago Teixeira Leite Ackel

Projeto Pimp My Carroça

artetude@gmail.com

Resumo: Este artigo aborda a pesquisa e o desenvolvimento de catorze carroças de catadores de recicláveis da Região Metropolitana de Belo Horizonte, enfatizando aspectos ergonômicos. A revisão de literatura contempla a gestão do lixo no Brasil, com ênfase no processo de reciclagem e na condição socioeconômica dos catadores. O objetivo geral foi melhorar a condição do catador por meio do projeto de produto. O método do Pimpex foi combinado com métodos de pesquisa $e$ desenvolvimento de produto, bem como amparado pela metodologia de ergonomia do produto. As etapas de desenvolvimento do projeto são descritas, considerando aspectos positivos e negativos da execução, além de correlacionar como as carroças produzidas implicaram em benefício para o trabalho e visibilidade dos catadores. Entende-se que os catadores são o elo mais vulnerável na cadeia de valor da reciclagem, e cujo valor do próprio trabalho ainda carece de reconhecimento social e do amparo de projetos como os que são propostos no escopo de atuação do Pimp My Carroça. Considerando a conjuntura do setor de reciclagem no Brasil, verifica-se a contribuição do Pimpex $\mathrm{BH}$ para a melhoria do trabalho dos catadores, a visibilidade dos mesmos e, por consequência, seu impacto socioambiental positivo.

Palavras-chave: Gestão do lixo, reciclagem, catadores, projeto de carroça.

Abstract: This paper discusses the research and development of fourteen carts for waste pickers who work in the Belo Horizonte metropolitan region, emphasizing ergonomics criteria. The literature review includes waste management in Brazil, with focus on the recycling process and the socioeconomic status of waste pickers. The overall objective was to improve the condition of the waste picker through product design. The method of Pimpex was combined with research and product development methods, as well as supported by the product ergonomics methodology. The description of the project development steps consider the positive and negative aspects of implementation, as well as correlates the benefits that the produced 
carts generated to the work and visibility of waste pickers. It is understood that waste pickers are the most vulnerable link in the recycling value chain. The value of their work itself still lacks social recognition and needs the support of projects such as those proposed within the scope of action of Pimp My Carroça. In the context of the recycling industry in Brazil, the Pimpex $\mathrm{BH}$ contributes to improve the work of waste pickers, to promote their visibility and, consequently, to foster their positive environmental impact.

Keywords: Waste management, recycling, waste pickers, cart design.

\section{INTRODUÇÃO}

\subsection{A reciclagem no Brasil}

Desde 1980, os consumidores têm sido encorajados a reciclar os resíduos, como papeis, latas, garrafas plásticas, vidros, pneus (CHANG et al, 1999). Nas discussões atuais sobre a gestão sustentável de resíduos sólidos, destaca-se o conceito de prevenção de resíduos. Na União Europeia, foi adotada uma política de gerenciamento de resíduos sólidos fundamentada em prevenção, reciclagem e disposição final reduzida (DIAS e BORTOLETO, 2014). Já no Brasil, a Política Nacional de Resíduos Sólidos - PNRS, em vigor desde 2010, cita a redução na fonte, a reciclagem e a disposição de resíduos, como algumas diretrizes (VILLAC, 2014). A Lei 12.305, que integra a PNRS, aborda os seguintes tópicos: ciclo de vida, logística reversa, reutilização, padrões sustentáveis de produção e consumo, manejo de resíduos sólidos, dentre outros, de modo a obrigar (estabelecendo regras e propondo punições criminais) as indústrias a manejar corretamente seus resíduos (DUARTE e CÂMARA, 2015).

Nesse contexto, a reciclagem se apresenta como uma prática central para uma gestão sustentável dos resíduos sólidos. Por definição, a reciclagem é o processo de coletar produtos, componentes e/ou materiais, desmontá-los (quando necessário), separá-los em categorias de materiais (como plásticos específicos, vidros, etc.) e processá-los em produtos, componentes e/ou materiais reciclados (BEAMON, 1999). Na Lei 12.305, a reciclagem é definida como:

Processo de transformação dos resíduos sólidos, que envolve a alteração de suas propriedades físicas, físico-químicas ou biológicas, com vistas a transformação em insumos ou novos produtos, observadas as condições e os padrões estabelecidos pelos órgãos competentes (PRESIDÊNCIA DA REPÚBLICA, 2016).

Pelo vetor da reciclagem, o beneficiamento de materiais pós-consumo desencadeia uma série de benefícios ambientais, econômicos e também sociais. Primeiramente, podemos citar como consequência direta da reciclagem a diminuição do volume de matéria enviada para aterros sanitários, o que prolonga a vida útil dessas estruturas. Outro benefício ambiental derivado do processo de reciclagem é a diminuição da extração de matérias-primas virgens, ou seja, a reciclagem também conduz à prevenção de resíduos sólidos na extração de recursos naturais (DIAS e BORTOLETO, 2014; JOHN e ZORDAN, 2001). 
A estruturação da indústria de reciclagem levou também à valorização econômica de materiais descartados. Esse processo propiciou a consolidação do mercado de materiais recicláveis. Nesse contexto, surge o termo "valoração de resíduos" como resultado econômico do processo de agregar valor aos produtos e materiais pós-consumo (TEODÓSIO et al, 2014). A atividade de coleta e encaminhamento de resíduos sólidos, que até então gerava apenas gastos, passou a ser uma atividade que gera retorno financeiro. $O$ sistema de reciclagem agrega tanto valor ambiental quanto econômico (LEITE, 2009). Tal valor econômico atribuído aos materiais descartados possibilita a sobrevivência de uma parcela da população em situação de vulnerabilidade social, muitas vezes excluída do mercado formal de trabalho. Observamos essa situação no Brasil, em que:

Um número significativo dessa população vive nas ruas, onde desenvolve o seu repertório de sobrevivência que envolve a coleta e reciclagem de materiais, o que é conhecido como "catação". E uma economia autocriada que reutiliza o lixo e os restos da cidade. A coleta de material reciclável às vezes alcança, ou ultrapassa, o salário mínimo (HARLAND e SANTOS, 2014).

Um processo inicial para a viabilização da reciclagem dos resíduos sólidos urbanos é a coleta em separado dos materiais a serem processados, a chamada coleta seletiva. Para que a implantação e implementação da coleta seletiva em cidades brasileiras sejam viáveis, os catadores de materiais recicláveis têm papel de destaque. Em muitos casos, os catadores já prestavam o serviço de coleta de recicláveis antes da implantação de programas de coleta seletiva pelas prefeituras.

A quantidade de resíduos recicláveis coletados anualmente através de programas oficiais de coleta seletiva representa apenas uma pequena fração do total de resíduos reciclados no país (TAB. 01).

TABELA 01 - Estimativa da participação dos programas de coleta seletiva formal (2008).

\begin{tabular}{l|l|l|l}
\hline Resíduos & $\begin{array}{l}\text { Quantidade de resíduos } \\
\text { reciclados no país } \\
\text { (mil t/ano) }\end{array}$ & $\begin{array}{l}\text { Quantidade recuperada por } \\
\text { programas oficiais de coleta } \\
\text { seletiva }\end{array}$ & $\begin{array}{l}\text { Participação da coleta } \\
\text { seletiva formal na } \\
\text { reciclagem total }\end{array}$ \\
\hline Metais & $9.817,8$ & 72,3 & $0,7 \%$ \\
\hline Papel/papelão & $3.827,9$ & 285,7 & $7,5 \%$ \\
\hline Plástico & $962,0 *$ & 170,3 & $17,7 \%$ \\
\hline Vidro & 489,0 & 50,9 & $10,4 \%$ \\
\hline Nota: *dado de 2007
\end{tabular}

Fonte: IPEA, 2012 apud TEODÓSIO et al, 2014.

Os dados supracitados refletem a ineficiência dos programas oficiais de coleta seletiva no Brasil e evidenciam a importância da cadeia informal de reciclagem formada pelos catadores. É através dessa cadeia informal que grande parte dos materiais recicláveis são reinseridos nos processos produtivos (TEODÓSIO et al, 2014).

\subsection{Os catadores}

Não há dados precisos quanto ao número de catadores existentes no Brasil. Um relatório publicado pelo Instituto de Pesquisa Econômica Aplicada - IPEA em 2012 baseia-se nos dados do Censo Demográfico do IBGE e na Pesquisa Nacional por 
Amostragem de Domicílios - PNAD de 2010, e estima a existência de 387.910 catadores no Brasil. No entanto, o estudo reconhece que esse número pode estar abaixo do quantitativo real. TEODÓSIO et al (2014) apontam para outras fontes que apresentam diferentes números, como a Pesquisa Nacional de Saneamento Básico de 2008 que identificou 70.449 catadores de materiais recicláveis (destaca-se que 5.635 são crianças menores de 14 anos); e a estimativa do Movimento Nacional dos Catadores - MNC de que existam 800 mil catadores no país (TEODÓsIO et al, 2014).

De acordo com os dados processados pelo IPEA (2010), a maioria dos catadores são homens negros de aproximadamente 40 anos. Ainda segundo o relatório do IPEA o rendimento médio do trabalho dos catadores varia entre $R \$ 459,00$ e $R \$ 619,00$, sendo $\mathrm{R} \$ 571,56$ a média para todo o país. Quanto à escolaridade, estima-se que aproximadamente $25 \%$ dos catadores com 25 anos ou mais completaram o ensino fundamental, e apenas 11\% completaram o ensino médio (IPEA, 2010).

Gradativamente, o trabalho dos catadores tem sido reconhecido como parte integrante da gestão de resíduos sólidos no Brasil. Essa conquista está ligada ao histórico de luta e auto-organização desse grupo, que transformou a atividade também em um movimento social. As primeiras associações e cooperativas de catadores surgiram no final dos anos 1980 em São Paulo (Coopamare) e início dos anos 1990 em Minas Gerais (Asmare). Em 2001, foi formado o Movimento Nacional dos Catadores (MNC) que reúne grupos de catadores e trabalhadores autônomos em todo o país.

A atividade profissional "Catador de Materiais Recicláveis" foi reconhecida pelo Ministério do Trabalho e Emprego em 2002. Em 2007, foi estabelecida a dispensa de licitação para contratação pública de cooperativas e associações de catadores. Em 2010, a PNRS determinou a inclusão dos catadores na gestão de resíduos sólidos, além de incentivar a formação de cooperativas e associações. Tais mudanças legislativas são importantes por validar constitucionalmente o trabalho dos catadores como agentes de limpeza urbana e possibilitar que sejam pagos pelo serviço que prestaram à cidade.

O reconhecimento legal da atividade dos catadores contribui para desfazer um dos estigmas ligados à essa atividade - o estigma da informalidade. Os catadores, no entanto, ainda enfrentam muitos problemas no seu trabalho diário como, por exemplo, o preconceito, o desrespeito e a invisibilidade. Para NAGLE (2013), o trabalho de coleta de resíduos é um exemplo de elemento "não notado" na vida diária, e os envolvidos são trabalhadores igualmente "não notados", invisíveis. O reconhecimento legal não necessariamente leva à aceitação social da atividade, que ainda é estigmatizada por lidar com materiais descartados e por ser realizada por uma parcela marginalizada da população.

\subsection{O projeto Pimp My Carroça}

Nesse âmbito, surgem projetos sociais que visam promover a visibilidade e a valorização do catador como indivíduo e profissional autônomo. Podemos citar os seguintes projetos: Catadores Saudáveis, Coleta Solidária, Cavalo de Lata, dentre outros. Destaca-se o projeto Pimp My Carroça, iniciado pelo artista Thiago Mundano, em 2012 na cidade de São Paulo. A saber, o projeto é entendido como: 
Um movimento que luta para tirar os catadores de materiais recicláveis da invisibilidade, promover a sua autoestima e sensibilizar a sociedade para a causa em questão, com ações criativas que utilizam o graffiti para conscientizar, engajar e transformar (PIMP MY CARROÇA, 2016).

Além de propor uma conscientização política e humanizada, o impacto social do projeto consiste diretamente na reforma e grafite das carroças, na doação de objetos de interface catador/carroça e equipamentos de proteção individual para os catadores, e em diversas atividades que vão do atendimento de saúde e higiene para o catador até intervenções urbanas propondo "vaga de carroças" e "reciclovias". Ao longo dos anos, o projeto já atendeu 496 catadores (que tiveram suas carroças reformadas e grafitadas, isto é, "pimpadas"), contou com 354 grafiteiros e artistas participantes, além de 1.429 voluntários participantes, em mais de 20 cidades no Brasil, na Bolívia e no Peru. Em 2015, o projeto Pimp My Carroça recebeu o "Prêmio de Água e Saneamento do Banco Interamericano de Desenvolvimento - FEMSA América Latina e no Caribe", na categoria Resíduos Sólidos.

\section{MATERIAIS E MÉTODOS}

Durante o segundo semestre de 2015, o projeto Pimpex, que integra o escopo de atuação do Pimp My Carroça, foi proposto como atividade didática para 15 alunos do 70 período de Engenharia de Produção na Faculdades Kennedy, na disciplina de "Planejamento e Projeto de Produto". O objetivo geral foi melhorar a condição do catador por meio do projeto de produto. Dentre os objetivos específicos, menciona-se a promoção da visibilidade do catador, a proposição de soluções para as carroças adequadas a cada catador, além da viabilização para os alunos de uma experiência projetual de impacto social. O método do Pimpex foi combinado com métodos de pesquisa e desenvolvimento de produto (BAXTER, 2000; ROZENFELD et al, 2006; MOREIRA, 2013), bem como amparado pela metodologia de ergonomia do produto (IIDA, 2005), a qual incluiu análise de verbalizações por meio de entrevistas e análise da tarefa do catador (QUADRO 01). 
QUADRO 01 - Metodologia do Pimpex BH

\begin{tabular}{|c|c|c|}
\hline N. & ETAPA & FERRAMENTAS DE AUXÍLIO E/OU FORMA DE VIABILIZAÇÃO \\
\hline 1 & $\begin{array}{l}\text { Compreensão do projeto } \\
\text { Pimp My Carroça }\end{array}$ & $\begin{array}{l}\text { Vídeos e materiais instrutivos, site e mídias sociais do projeto, além } \\
\text { de links diversos correlacionados. }\end{array}$ \\
\hline 2 & Prospecção dos catadores & $\begin{array}{l}\text { Ficha de entrevista estruturada, própria do projeto; fotos com o } \\
\text { catador; verbalizações buscando compreender, com sensibilidade, o } \\
\text { indivíduo e o trabalhador. Foram selecionados } 14 \text { catadores } \\
\text { aleatórios na Região Metropolitana de Belo Horizonte, todavia } \\
\text { próximos do local-base (trabalho ou casa) de cada aluno. }\end{array}$ \\
\hline 3 & Prospecção dos artistas & $\begin{array}{l}\text { Grafiteiros e artistas de rua reconhecidos e novatos foram } \\
\text { convidados a pintar as carroças dos catadores. O perfil profissional e } \\
\text { portfólio online de cada artista foi analisado durante cinco meses. }\end{array}$ \\
\hline 4 & $\begin{array}{l}\text { Pesquisa de produtos } \\
\text { concorrentes, produtos } \\
\text { similares e materiais }\end{array}$ & $\begin{array}{l}\text { Alunos pesquisaram imagens de carroças, produtos semelhantes e } \\
\text { objetos de interface alternativa usados no transporte de materiais } \\
\text { recicláveis. Também pesquisaram características dos materiais. }\end{array}$ \\
\hline 5 & Orçamento de materiais & $\begin{array}{l}\text { Cada aluno apresentou um orçamento para sua carroça, feito junto } \\
\text { a serralheiros e empresas de materiais. Todos os orçamentos foram } \\
\text { refeitos, buscando reduzir os valores pela metade. }\end{array}$ \\
\hline 6 & $\begin{array}{l}\text { Campanha de financiamento } \\
\text { coletivo }\end{array}$ & $\begin{array}{l}\text { Realizada por meio do site Catarse, que propôs condições especiais } \\
\text { para este Pimpex de maior complexidade técnica e de imprevistos. }\end{array}$ \\
\hline 7 & $\begin{array}{l}\text { Geração de ideias, conceitos e } \\
\text { desenhos preliminares }\end{array}$ & $\begin{array}{l}\text { Por meio do uso de diversas ferramentas de criatividade, os alunos } \\
\text { geraram conceitos (em palavras) para suas carroças, e então } \\
\text { desenhos (também chamado de "geração de alternativas"). }\end{array}$ \\
\hline 8 & $\begin{array}{l}\text { Análise ergonômica do } \\
\text { trabalho do catador }\end{array}$ & $\begin{array}{l}\text { Durante um dia, os alunos se colocaram no lugar de uma catadora, } \\
\text { carregando-a em sua carroça, aprendendo sobre dimensões, peso, } \\
\text { formas de locomoção, adequações da interface carroça-catador }\end{array}$ \\
\hline 9 & $\begin{array}{l}\text { Divulgação do projeto para } \\
\text { obter doações }\end{array}$ & $\begin{array}{l}\text { Produção de peças publicitárias para mídias sociais. Panfletagem no } \\
\text { centro de } \mathrm{BH} \text {. Execução de um grafite de } 3 \mathrm{~m} \text { em local movimentado } \\
\text { e central de } \mathrm{BH} \text {. Releases em jornais impresso. Participação da } \\
\text { organizadora em programas de TV e rádios. }\end{array}$ \\
\hline 10 & $\begin{array}{l}\text { Desenvolvimento de } \\
\text { desenhos e mock-ups }\end{array}$ & $\begin{array}{l}\text { Os desenhos de cada aluno tiveram orientação da professora, } \\
\text { quanto a expressar um conceito/ideia e propor soluções para } \\
\text { atributos diversos como leveza, rapidez, facilidade de manusear, } \\
\text { conforto, etc. }\end{array}$ \\
\hline 11 & Detalhamento técnico & Desenvolvimento de croquis técnicos e desenho final. \\
\hline 12 & Reforma das carroças & $\begin{array}{l}\text { Cada aluno buscou o apoio de profissionais experientes em } \\
\text { serralheria e borracharia, além de buscar por metais e rodas. }\end{array}$ \\
\hline 13 & Logística das carroças & $\begin{array}{l}\text { Coube a voluntários de outro projeto e a um grupo de alunos do } 10 \text { ㅇ } \\
\text { período, na disciplina de "Projeto de Fábrica e Instalações } \\
\text { Industriais" viabilizar carretos e caminhonetes, e propor a rota. }\end{array}$ \\
\hline 14 & Grafite das carroças & $\begin{array}{l}\text { Participaram sete homens e sete mulheres artistas, que dispuseram } \\
\text { também de seus materiais. Foram doadas ainda } 14 \text { latas de spray. }\end{array}$ \\
\hline 15 & $\begin{array}{l}\text { Entrega dos kits pimpadores } \\
\text { do Pimpex }\end{array}$ & $\begin{array}{l}\text { Os kits foram entregues em duas etapas aos catadores: uma parte } \\
\text { durante o dia do evento, e outra parte dos itens após o evento. }\end{array}$ \\
\hline 16 & Relato do evento & $\begin{array}{l}\text { No dia do evento, foram coletadas verbalizações com os catadores. } \\
\text { Após a realização do evento, foram feitas reuniões distintas com } \\
\text { alunos, voluntários, apoiadores, artistas e com os organizadores, } \\
\text { buscando avaliar os aspectos positivos e os a serem melhorados. }\end{array}$ \\
\hline
\end{tabular}


Uma das principais características que distingue o Pimp My Carroça de outros projetos em prol dos catadores de recicláveis é o "kit pimpador" (FIG. 01), que consiste em ferramentas, objetos de interface carroça/catador e equipamentos de proteção individual (EPIs).

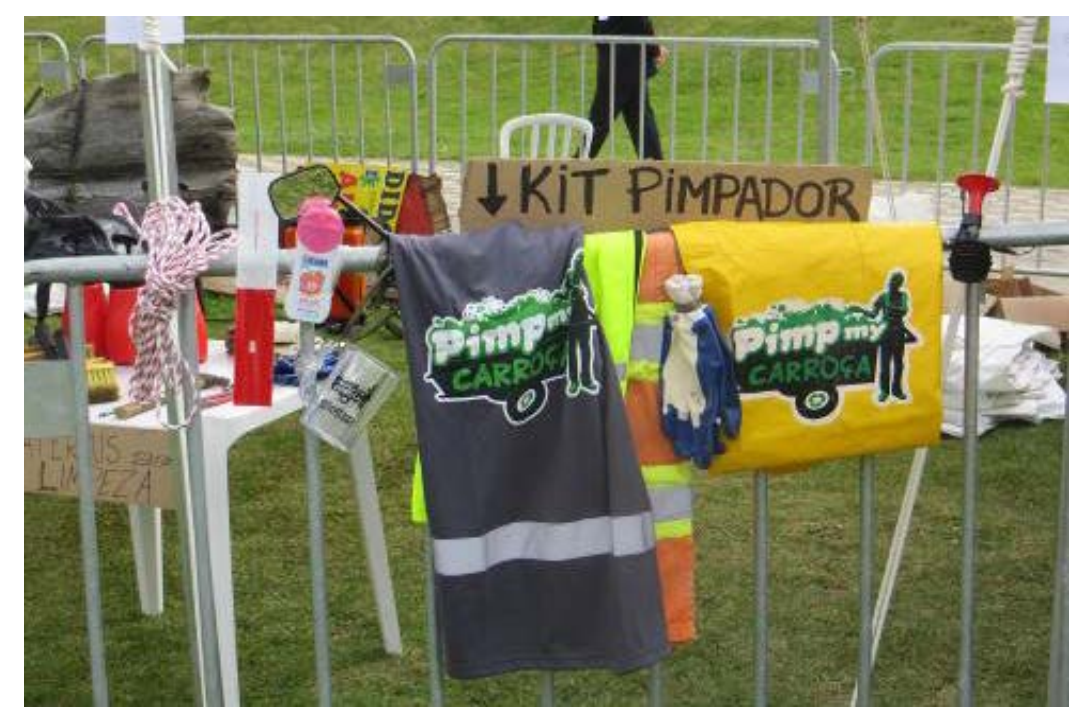

Figura 01 - Kit Pimpador do projeto Pimp My Carroça Fonte: PIMP MY CARROÇA (2016).

\section{DESENVOLVIMENTO}

\section{Equipamentos de proteção individual para os catadores}

O kit pimpador do Pimpex BH conteve os seguintes EPIs: buzina, espelhos retrovisores, fitas refletivas, luvas emborrachadas, protetor solar, coletes e calças alaranjados com faixas refletivas, camisetas do projeto com faixas refletivas (estampadas "Catador com muito orgulho!") e capa de chuva personalizada. Houve ainda a doação de camisetas cinzas com faixas refletivas nas mangas, na frente e nas costas, feitas de algodão orgânico e com estampas personalizadas do projeto, pela empresa de moda ecológica mineira Grama. Todos os itens estavam de acordo com os tamanhos $\mathrm{P}, \mathrm{M}$ ou $\mathrm{G}$ de cada catador. Além dos EPIs, também foram entregues objetos de auxílio, como balança portátil, sacos de ráfia, $10 \mathrm{~m}$ de corda, bem como objetos de finalidade emocional, tal canecas e adesivos do projeto, para que os catadores tenham uma recordação do mesmo. Em outros projetos Pimpex ou Pimp My Carroça, o kit pimpador pode conter outros itens, como óculos escuros e óculos de grau.

Ressalta-se que os EPIs são válidos justamente por não pertencer ao escopo do projeto Pimpex melhorar a segurança do posto de trabalho do catador, isto é, os EPIs são necessários neste caso dado a inviabilidade da articulação política e interferência necessária nos locais de atuação do catador, que são as vias públicas, os depósitos formais e informais. Contrariando a premissa de adaptar o trabalho, o ambiente, as máquinas e os equipamentos ao homem (IIDA, 2005), o projeto busca adaptar o homem ao trabalho. Em contrapartida, foi verificado nas verbalizações dos catadores a sua aprovação e boa aceitação dos EPIs. 


\subsection{Descrição de aspectos positivos e negativos do desenvolvimento}

Por meio de entrevistas estruturadas, conjugando dados pessoais e profissionais, o perfil socioeconômico dos catadores participantes confirmou os dados do IPEA (2010). Destaca-se o predomínio de uma informação relevante sobre o trabalho: a maioria dos catadores antes trabalhava na construção civil e, não conseguindo mais trabalhar com carteira assinada, viu no ofício de catador um trabalho viável. A maioria reconhece o valor do seu trabalho para o meio ambiente e a cidade, dizendo sobre si mesmos que são "catadores de recicláveis" e não "catadores de lixo". Por exemplo, a verbalização de um dos catadores entrevistados, o senhor João Francisco dos Santos, de 93 anos de idade: "Amo o que eu faço. Não vou deixar de fazer o que eu gosto!"

O projeto contou com alguns desafios e imprevistos, podendo ser citados: (1) a tragédia do rompimento da barragem de Mariana (que direcionou o foco da mídia e dos doadores, implicando em ajustes na divulgação do projeto e no cronograma); (2) alguns catadores inicialmente prospectados não foram mais localizados ou desistiram de participar; (3) obtenção de doações de materiais; (4) bater a meta alta da campanha no Catarse, orçada em $\mathrm{R} \$ 16.130,00$ para executar todo o projeto.

Dentre os pontos positivos, ressalta-se o alto comprometimento dos alunos que, mesmo tendo a opção de fazerem o projeto em dupla e atender somente sete catadores, preferiram esforçar-se no cumprimento de todas as etapas do projeto com êxito. Uma das atividades realizadas pela turma foi a análise da tarefa do catador, tendo cada aluno se colocado no lugar da catadora Maria Helena, 53 anos, para compreender seu trabalho e sua carroça (FIG. 02). Em sua carroça, a catadora foi carregada por cada um dos alunos pela área central de Belo Horizonte, ocupando as vias públicas tal um carro, e buscando divulgar o projeto por meio de panfletos e conversas com pedestres e motoristas. Para ilustrar um dos aspectos da tarefa do catador, menciona-se que a catadora em questão, há 16 anos no ofício, moradora de rua, e pesando $54 \mathrm{~kg}$, carrega diariamente 386 ou $387 \mathrm{~kg}$ de materiais recicláveis. Segundo Maria Helena, é "o hábito de trabalhar" que permite carregar tal peso.

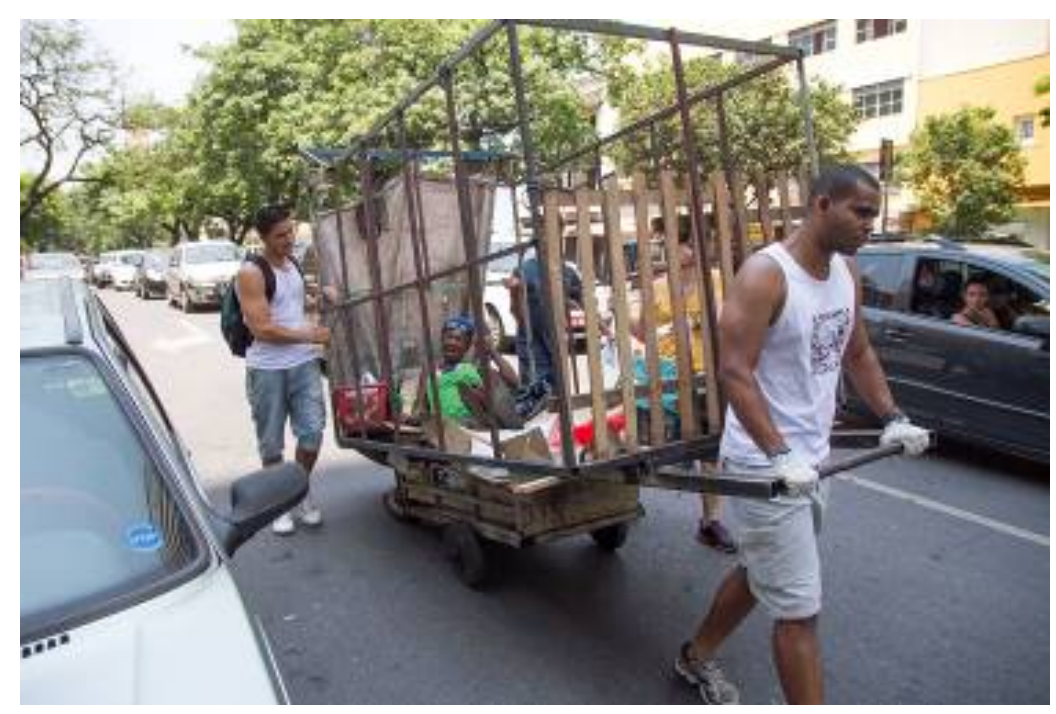

Figura 02 - Análise da tarefa do catador pelos alunos de engenharia de produção. Fonte: Elaborado pelos autores, com base em pesquisa realizada (2015). 
A maioria das carroças foi reformada a partir da carroça preexistente de cada catador. Todavia, algumas delas foram totalmente produzidas pelos alunos, nos casos dos catadores em que: (1) a carroça apresentava excesso de ferrugem; (2) utilizava carrinho de supermercado ao invés de carroça; (3) não possuía carroça. Algumas carroças reformadas eram de madeira, enquanto outras de estrutura metálica. Como exemplo, tem-se a carroça inteiramente enferrujada da catadora Ciderlande dos Santos (FIG. 03), que sustenta três filhos com seu trabalho e mencionou na entrevista estruturada que o estado de sua carroça estava bom.

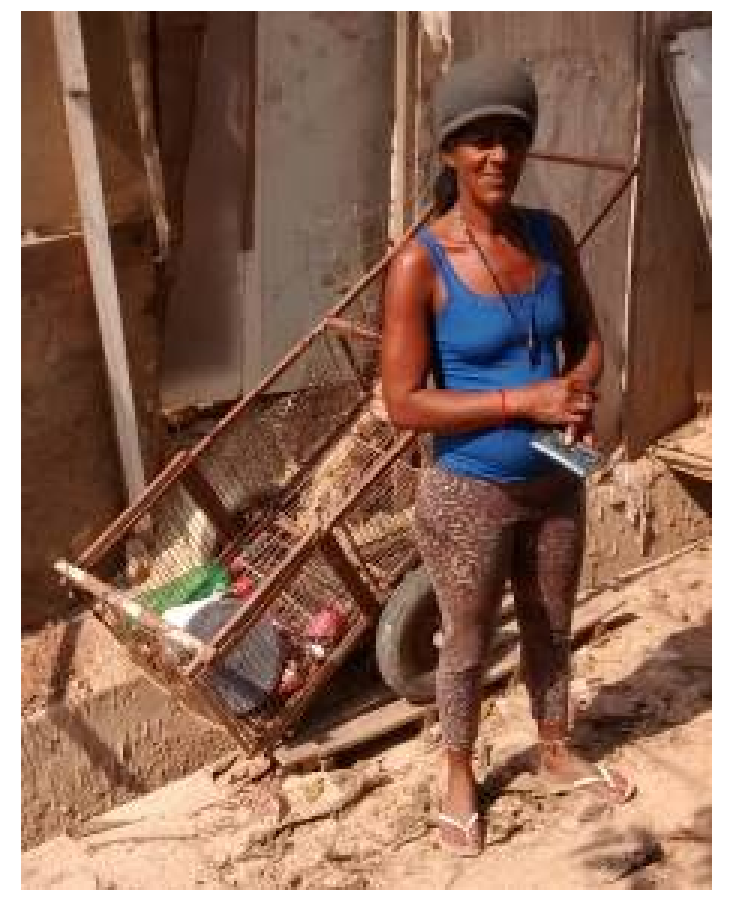

Figura 03 - Catadora Ciderlande dos Santos e carroça enferrujada.

Fonte: Aluna Gabrielle Moreira (2015).

No dia do evento, que englobava ainda outras atividades como dança e doação de roupas, livros e refeições, as carroças foram levadas para a calçada de uma das principais avenidas de Belo Horizonte, a Av. Afonso Pena. Os catadores e suas famílias participaram de algumas atividades, enquanto as carroças eram pintadas. A participação dos artistas de rua e grafiteiros foi engajada e amistosa, tendo todos comparecido no dia do evento e dialogado com os catadores sobre suas cores, desenhos e mensagens preferidas, atendendo o catador com sua arte (FIG. 04).

A equipe do Projeto Pimp My Carroça, em São Paulo, mostrou-se constantemente flexível, proativa, comunicativa e em sinergia com a equipe de Belo Horizonte. A equipe de São Paulo, mais os alunos e os artistas, divulgaram o projeto amplamente em suas mídias sociais. O Pimpex BH também recebeu destaque em mídias diversas de amplo alcance em Minas Gerais (DUARTE, 2016), como jornal Estado de Minas, jornal O Tempo, TV Rede Minas, TV BH News, Rádio UFMG, Rádio Itatiaia, dentre outras mídias, contribuindo para dar visibilidade ao trabalho do catador perante a sociedade. 


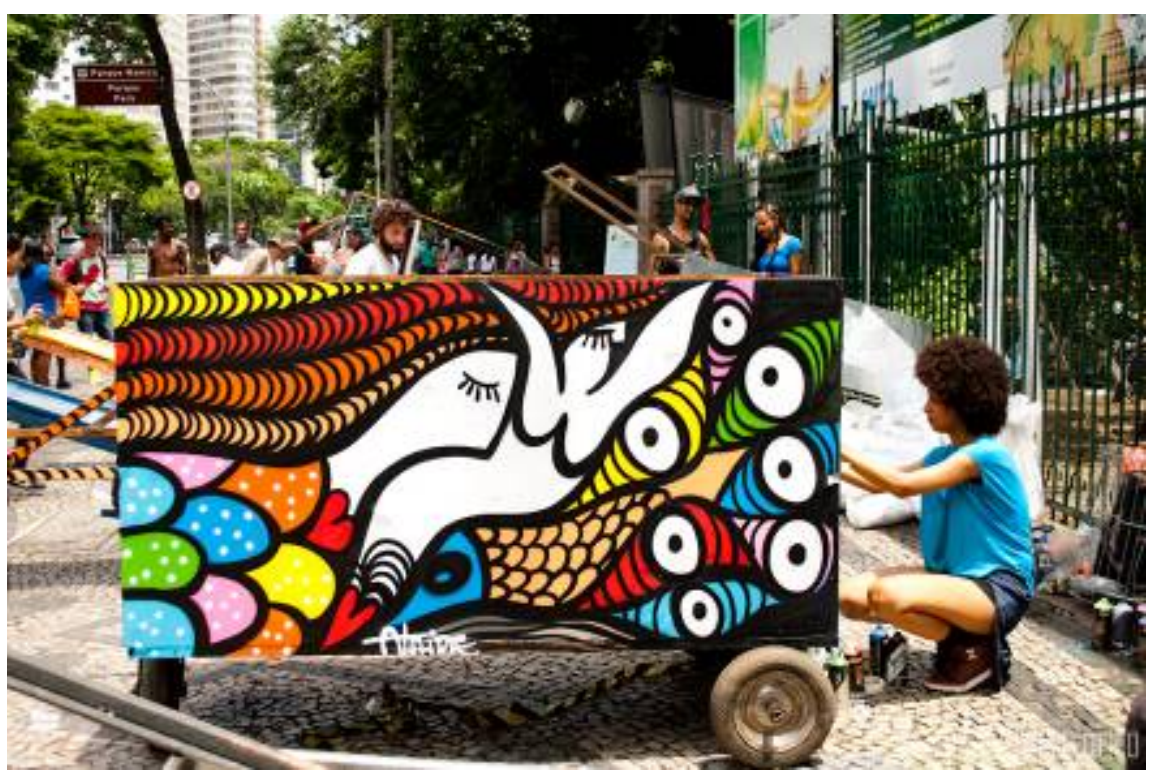

Figura 04 - Carroça produzida para a catadora Ciderlande dos Santos, com grafite dos artistas Ataíde Miranda, Criola e DMS.

Fonte: Fotógrafo João Vitor Teófilo (2015).

\section{CONSIDERAÇÕES FINAIS}

A realização do projeto Pimpex $\mathrm{BH}$ mostrou-se viável mediante $\mathrm{o}$ alto engajamento e flexibilidade de todas as partes envolvidas. A metodologia utilizada pode ser replicada para outras disciplinas correlatas com o projeto de produto, considerando o fator localidade dos catadores, a logística de atendimento, o comprometimento dos envolvidos e tendo como foco atender os catadores. As catorze carroças produzidas, conjugadas com objetos de interface catador/carroça e com o conjunto de EPIs, mostraram-se eficientes em cumprir os objetivos propostos do projeto, atendendo as especificidades de cada um dos catadores. Entende-se que os catadores são o elo mais vulnerável na cadeia de valor da reciclagem, e cujo valor do próprio trabalho ainda carece de reconhecimento social e do amparo de projetos como os que são propostos no escopo de atuação do Pimp My Carroça. Considerando a conjuntura do setor de reciclagem no Brasil, verifica-se a contribuição do Pimpex BH para a melhoria do trabalho dos catadores, a visibilidade dos mesmos e, por consequência, seu impacto socioambiental.

\section{REFERÊNCIAS}

BAXTER, M. Projeto de produto: guia prático para o design de novos produtos. São Paulo: Blucher, 2000, 260 p.

BEAMON, B. M. Designing the green supply chain. Logistics Information Management, v. 12,1999, p. 332-342.

CHANG, Y., CHEN, H., FRANCIS, S. Market applications for recycled postconsumer fibers. Family and Consumer Sciences Research Journal, v. 27, n. 3, 1999, p. 320-340.

DIAS, S. L. F. G.; BORTOLETO A. P. A Prevenção de Resíduos Sólidos e o Desafio da Sustentabilidade. In: LOSCHIAVO, M. C. S. (Coord.). Design, Resíduo \& Dignidade. São Paulo: Editora Olhares, 2014, p. 91-113. 
DUARTE, L, CÂMARA, T. Logística reversa e competitividade para os resíduos têxteis no polo de moda de Belo Horizonte. Anais do Colóquio Internacional de Design, Belo Horizonte, 2015, 15 p.

DUARTE, L. Moda Ética - resultados para o termo “pimpex bh". Disponível em: < http://modaetica.com.br > Acesso em: 10 jan. 2016.

HARLAND R.; SANTOS, M. C. L. O trabalho com resíduos para dignificar a existência humana através do uso de colagem como um design espontâneo. In: LOSCHIAVO, M. C. S. (Coord.). Design, Resíduo \& Dignidade. São Paulo: Editora Olhares, 2014, p. 75-89. IIDA, I. Ergonomia: projeto e produção. São Paulo: Edgard Blücher, 2005, 614 p.

IPEA. Situação social das catadoras e dos catadores de material reciclável e reutilizável (2013). Disponível em: <

http://www.ipea.gov.br/agencia/images/stories/PDFs/situacao_social/131219_relatori o_situacaosocial_mat_reciclavel_brasil.pdf > Acesso em: 10 fev. 2016

JOHN, V. M.; ZORDAN, S. E. Research \& development methodology for recycling residues as building materials. Waste Management, v. 21, 2001, p. 213-219.

LEITE, P. R. Logística reversa: meio ambiente e competitividade. Pearson Prentice Hall: São Paulo, 2009, 240 p.

MOREIRA, D. A. Administração da produção e operações. São Paulo: Cengage Learning, 2013, $624 \mathrm{p}$.

NAGLE, R. Picking up: on the streets and behind the trucks with the sanitation workers of New York City. New York: Farrar, Straus and Giroux, 2013. p. 22.

PIMP MY CARROÇA. Disponível em: < http://pimpmycarroca.com/ > Acesso em: 09 fev. 2016.

PRESIDÊNCIA DA REPÚBLICA. Lei 12.305. Disponível em: < http://www.planalto.gov.br/ccivil_03/_ato2007-2010/2010/lei//12305.htm> Acesso em 08 fev. 2016.

ROZENFELD, H. et al. Gestão de desenvolvimento de produtos - uma referência para a melhoria do processo. São Paulo: Saraiva, 2006, 542 p.

TEODÓSIO, A. S. S.; DIAS, S. L. F. G.; SANTOS, M. C. L. Reciclagem no Interstício das Relações Intersetoriais: a Política Nacional de Resíduos Sólidos e os desafios para a inclusão social e produtiva dos catadores. In: LOSCHIAVO, M. C. S. (Coord.). Design, Resíduo \& Dignidade. São Paulo: Editora Olhares, 2014, p. 231-267.

VILLAC, T. A construção da Política Nacional de Resíduos Sólidos. In: LOSCHIAVO, M. C. S. (Coord.). Design, Resíduo \& Dignidade. São Paulo: Editora Olhares, 2014, p. 149159. 